\title{
SOME RELATED FIXED POINT THEOREMS FOR MULTIVALUED MAPPINGS ON TWO METRIC SPACES
}

\author{
Biçer Ö. ${ }^{1}$, Olgun M. ${ }^{2}$, Alyildiz T. ${ }^{2}$, Altun I. ${ }^{3}$
}

\begin{abstract}
The definition of related mappings was introduced by Fisher in 1981. He proved some theorems about the existence of fixed points of single valued mappings defined on two complete metric spaces and relations between these mappings. In this paper, we present some related fixed point results for multivalued mappings on two complete metric spaces. First we give a classical result which is an extension of the main result of Fisher to the multivalued case. Then considering the recent technique of Wardowski, we provide two related fixed point results for both compact set valued and closed bounded set valued mappings via $F$-contraction type conditions.

Key words and phrases: fixed point, complete metric space, F-contraction.
\end{abstract}

\footnotetext{
${ }^{1}$ Department of Electronic Communication Technology, Vocational School, Medipol University, 34810, Istanbul, Turkey

2 Department of Mathematics, Faculty of Science, Ankara University, 06100, Tandogan, Ankara, Turkey

${ }^{3}$ Department of Mathematics, Faculty of Science and Arts, Kirikkale University, 71450, Yahsihan, Kirikkale, Turkey

E-mail: ozgeb89@hotmail.com (Biçer Ö.), olgun@ankara.edu.tr(Olgun M.),

tugcekavuzlu@hotmail.com(Alyıldız T.), ishakaltun@yahoo.com (Altun I.)
}

\section{INTRODUCTION AND PRELIMINARIES}

The well-known Banach contraction mapping principle plays crucial role in the functional analysis and ensures the existence and uniqueness of a fixed point on a complete metric space. By considering this principle several authors generalized it in different ways and this thought has opened that there exist various types of contractions using different mappings in two metric spaces. Some of authors wonder whether each of two contraction mappings on two complete metric spaces has a fixed point and what is the relation between them.

After 1981, Fisher and others gave the definition of related mappings and proved that they have fixed points which are related to each other [4-7].

Definition 1. Let $(X, d)$ and $(Y, \rho)$ be two metric spaces, $T: X \rightarrow Y$ and $S: Y \rightarrow X$ are two mappings. If there exist $x \in X$ and $y \in Y$ such that $T x=y$ and $S y=x$, then the pair $(T, S)$ is called related mappings.

Fisher [4] proved the theorem given in the following and then most of authors generalized it using different contractions on metric spaces.

Theorem 1. Let $(X, d)$ and $(Y, \rho)$ be two complete metric spaces, $T: X \rightarrow Y$ and $S: Y \rightarrow X$ mappings satisfying the following equations:

$$
\begin{aligned}
& d(S y, S T x) \leq c \max \{d(x, S y), d(x, S T x), \rho(y, T x)\}, \\
& \rho(T x, T S y) \leq c \max \{\rho(y, T x), \rho(y, T S y), d(x, S y)\}
\end{aligned}
$$

$\overline{\mathrm{y} \triangle \mathrm{K} 515.126 .4}$

2010 Mathematics Subject Classification: 54H25, 47H10. 
for all $x \in X$ and $y \in Y$, where $0 \leq c<1$. Then ST has a unique fixed point $z \in X$ and TS has a unique fixed point $w \in Y$. Further $T$ and $S$ are related mappings.

Let $(X, d)$ be a metric space. $P(X)$ denotes the family of all nonempty subsets of $X, C(X)$ denotes the family of all nonempty closed subsets of $X, C B(X)$ denotes the family of all nonempty closed and bounded subsets of $X$, and $K(X)$ denotes the family of all nonempty compact subsets of $X$. It is clear that, $K(X) \subseteq C B(X) \subseteq P(X)$. For $A, B \in C B(X)$, let

$$
H(A, B)=\max \left\{\sup _{x \in A} D(x, B), \sup _{y \in B} D(y, A)\right\},
$$

where $D(x, B)=\inf \{d(x, y): y \in B\}$ and $D(y, A)=\inf \{d(x, y): x \in A\}$. Then $H$ is called generalized Pompeiu-Hausdorff distance on $C(X)$ and it is well known that $H$ is a metric on $C B(X)$, which is called Pompeiu-Hausdorff metric induced by $d$. In 1969, Nadler [9] gave the definition of multivalued contraction using Hausdorff metric and proved that every multivalued contraction mapping has a fixed point in complete metric spaces.

Theorem 2 ([1]). Let $(X, d)$ be a metric space, $A$ and $B$ are nonempty subsets of $X$. If $A$ is compact then there exists $p \in A$ such that $D(A, B)=D(p, B)$.

Remark 1. Let $(X, d)$ be a metric space, $x \in X$, and $A$ is a nonempty compact subset of $X$. Then there exists $a \in A$ such that $d(x, a)=D(x, A)$.

Lemma 1 ([9]). Let $(X, d)$ be metric space, $A, B \in C B(X)$ and $a \in A$. Then there exists $b \in B$ such that

$$
d(a, b) \leq q H(A, B)
$$

for all $q>1$.

Theorem 3 ([9]). Let $(X, d)$ be a complete metric space and $T: X \rightarrow C B(X)$ be a mapping. If there exists $c \in(0,1)$ such that

$$
H(T x, T y) \leq c d(x, y)
$$

for all $x \in X$, then $T$ has a fixed point.

In 2012 Wardowski [8] introduced a new concept of $F$-contraction on complete metric space. Let $F:(0, \infty) \rightarrow \mathbb{R}$ be a function. Consider the following conditions:

(F1) $F$ is strictly increasing, i.e., for all $\alpha, \beta \in(0, \infty)$ such that $\alpha<\beta, F(\alpha)<F(\beta)$;

(F2) for each sequence $\left\{\alpha_{n}\right\}$ of positive numbers $\lim _{n \rightarrow \infty} \alpha_{n}=0$ if and only if $\lim _{n \rightarrow \infty} F\left(\alpha_{n}\right)=-\infty$;

(F3) there exists $k \in(0,1)$ such that $\lim _{\alpha \rightarrow 0^{+}} \alpha^{k} F(\alpha)=0$;

(F4) $F(\inf A)=\inf F(A)$ for all $A \subset(0, \infty)$ with $\inf A>0$.

$\digamma$ denotes the set of all functions satisfying $(\mathrm{F} 1)-(\mathrm{F} 3)$ and $\digamma_{*}$ denotes the set of all functions satisfying (F1)-(F4). It is clear that $\digamma * \subset \digamma$.

Definition $2([2,3])$. Let $(X, d)$ be a metric space and $T: X \rightarrow C B(X)$ be a mapping. Then $T$ is a multivalued $F$-contraction if $F \in \digamma$ and there exists $\tau>0$ such that

$$
\forall x, y \in X[H(T x, T y)>0 \Longrightarrow \tau+F(H(T x, T y)) \leq F(d(x, y))] .
$$


Theorem $4([2,3])$. Let $(X, d)$ be a complete metric space and $T: X \rightarrow C B(X)$ be a multivalued $F$-contraction. Then $T$ has a fixed point in $X$.

The main purpose of this paper it to present some related fixed point results for multivalued mappings on two complete metric spaces.

\section{MAin Result}

First we present the multivalued version of Theorem 1.

Let $(X, d)$ be a metric space, $T: X \rightarrow C B(Y)$ and $S: Y \rightarrow C B(X)$ be two mappings. Then for $u \in X$ we denote $S T u$ by

$$
S T u=\bigcup_{w \in T u} S w .
$$

Similarly we can denote the set $T S v$ for $v \in Y$. If there exists a point $u \in X$ such that $u \in S T u$, then $u$ is called fixed point of $S T$.

Theorem 5. Let $(X, d)$ and $(Y, \rho)$ be two complete metric spaces, $T: X \rightarrow C B(Y)$ and $S: Y \rightarrow$ $C B(X)$ be two mappings satisfying the following inequalities

$$
\begin{aligned}
& H_{1}(S y, S z) \leq c \max \left\{D_{1}(x, S y), D_{1}(x, S z), \rho(y, z)\right\}, \\
& H_{2}(T x, T w) \leq c \max \left\{D_{2}(y, T x), D_{2}(y, T w), d(x, w)\right\},
\end{aligned}
$$

for all $x \in X, y \in Y, z \in T x$ and $w \in S y$, where $0<c<1, H_{1}$ and $H_{2}$ are Pompeiu-Hausdorff metrics on $C B(X)$ and $C B(Y)$ respectively. Then $S T$ has a fixed point $u \in X$ and $T S$ has a fixed point $v \in Y$. Further, $u \in S v$ and $v \in T u$.

Proof. Let $x_{0}$ be an arbitrary point in $X$. As $S y$ and $T x$ are nonempty for all $x \in X$ and $y \in Y$, we can choose $y_{1} \in T x_{0}$ and $x_{1} \in S y_{1}$. If $x_{1} \in S T x_{1}$ and $y_{1} \in T S y_{1}$, then $x_{1}$ and $y_{1}$ are fixed points of ST and TS respectively. Now assume that $x_{1} \notin S T x_{1}$ or $y_{1} \notin T S y_{1}$.

Let $q>1$ such that $q c<1$. Applying inequalities (1) and (3), there exists $y_{2} \in T x_{1}$ such that

$$
\begin{aligned}
\rho\left(y_{1}, y_{2}\right) & \leq q H_{2}\left(T x_{0}, T x_{1}\right) \leq q c \max \left\{D_{2}\left(y_{1}, T x_{0}\right), D_{2}\left(y_{1}, T x_{1}\right), d\left(x_{0}, x_{1}\right)\right\} \\
& \leq q c \max \left\{H_{2}\left(T x_{0}, T x_{1}\right), d\left(x_{0}, x_{1}\right)\right\} \leq q c d\left(x_{0}, x_{1}\right)
\end{aligned}
$$

from which it follows that

$$
\rho\left(y_{1}, y_{2}\right) \leq q c d\left(x_{0}, x_{1}\right) .
$$

Now applying inequalities (1) and (2), there exists $x_{2} \in S y_{2}$ such that

$$
\begin{aligned}
d\left(x_{1}, x_{2}\right) & \leq q H_{1}\left(S y_{1}, S y_{2}\right) \leq q c \max \left\{D_{1}\left(x_{1}, S y_{1}\right), D_{1}\left(x_{1}, S y_{2}\right), \rho\left(y_{1}, y_{2}\right)\right\} \\
& \leq q c \max \left\{H_{1}\left(S y_{1}, S y_{2}\right), \rho\left(y_{1}, y_{2}\right)\right\}=q c \rho\left(y_{1}, y_{2}\right)
\end{aligned}
$$

from which it follows that

$$
d\left(x_{1}, x_{2}\right) \leq q c \rho\left(y_{1}, y_{2}\right) .
$$

By applying inequalities (1) and (3), there exists $y_{n+1} \in T x_{n}$ such that

$$
\begin{aligned}
\rho\left(y_{n}, y_{n+1}\right) & \leq q H_{2}\left(T x_{n-1}, T x_{n}\right) \leq q c \max \left\{D_{2}\left(y_{n}, T x_{n-1}\right), D_{2}\left(y_{n}, T x_{n}\right), d\left(x_{n-1}, x_{n}\right)\right\} \\
& \leq q c \max \left\{H_{2}\left(T x_{n-1}, T x_{n}\right), d\left(x_{n-1}, x_{n}\right)\right\} \leq q c d\left(x_{n-1}, x_{n}\right)
\end{aligned}
$$


for all $n \in \mathbb{N}$, and similarly, applying inequalities (1) and (2), there exists $x_{n+1} \in S y_{n+1}$ such that

$$
\begin{aligned}
d\left(x_{n}, x_{n+1}\right) & \leq q H_{1}\left(S y_{n}, S y_{n+1}\right) \leq q c \max \left\{D_{1}\left(x_{n}, S y_{n}\right), D_{1}\left(x_{n}, S y_{n+1}\right), \rho\left(y_{n}, y_{n+1}\right)\right\} \\
& \leq q c \max \left\{H_{1}\left(S y_{n}, S y_{n+1}\right), \rho\left(y_{n}, y_{n+1}\right)\right\}=q c \rho\left(y_{n}, y_{n+1}\right)
\end{aligned}
$$

from which it follows that

$$
\rho\left(y_{n}, y_{n+1}\right) \leq q H_{2}\left(T x_{n-1}, T x_{n}\right) \leq q c d\left(x_{n-1}, x_{n}\right) \leq \cdots \leq(q c)^{n+1} d\left(x_{0}, x_{1}\right)
$$

and

$$
d\left(x_{n}, x_{n+1}\right) \leq(q c) \rho\left(y_{n}, y_{n+1}\right) \leq(q c)^{2} d\left(x_{n-1}, x_{n}\right) \leq \cdots \leq(q c)^{n+2} d\left(x_{0}, x_{1}\right) .
$$

Letting $n \rightarrow \infty$ in (4) and (5) we obtain

$$
\lim _{n \rightarrow \infty} d\left(x_{n}, x_{n+1}\right)=0 \quad \text { and } \quad \lim _{n \rightarrow \infty} \rho\left(y_{n}, y_{n+1}\right)=0 .
$$

In order to show that $\left\{x_{n}\right\}$ and $\left\{y_{n}\right\}$ are Cauchy sequences consider $m, n \in \mathbb{N}$ such that $m>n$. From (5) and triangular inequality we write

$$
d\left(x_{n}, x_{m}\right) \leq \sum_{i=n}^{m-1} d\left(x_{i}, x_{i+1}\right) \leq \sum_{i=n}^{m-1}(q c)^{i+2} d\left(x_{0}, x_{1}\right) \leq d\left(x_{0}, x_{1}\right) \sum_{i=n}^{\infty}(q c)^{i+2},
$$

where $q c \in(0,1)$. From the convergence of the series $\sum_{i=-2}^{\infty}(q c)^{i+2}$ we obtain that $\left\{x_{n}\right\}$ is Cauchy sequence in $X$. Similarly using (4), we can see that $\left\{y_{n}\right\}$ is Cauchy sequence in $Y$. Since $(X, d)$ and $(Y, \rho)$ are complete metric spaces, the sequences $\left\{x_{n}\right\}$ and $\left\{y_{n}\right\}$ converge to some point $u \in X$ and $v \in Y$ respectively.

Now suppose $u \notin S v$ or $v \notin T u$. If $u \notin S v$, then there exists a number $n_{0} \in \mathbb{N}$ such that $D_{1}\left(S v, x_{n+1}\right)>0$ for $n>n_{0}$. Therefore, applying inequality (2), we have

$$
\begin{aligned}
D_{1}\left(S v, x_{n+1}\right) & \leq H_{1}\left(S v, S y_{n+1}\right) \leq c \max \left\{D_{1}\left(x_{n}, S v\right), D_{1}\left(x_{n}, S y_{n+1}\right), \rho\left(v, y_{n+1}\right)\right\} \\
& \leq c \max \left\{D_{1}\left(x_{n}, S v\right), d\left(x_{n}, x_{n+1}\right), \rho\left(v, y_{n+1}\right)\right\} .
\end{aligned}
$$

Letting $n \rightarrow \infty$ we get

$$
D_{1}(S v, u) \leq c D_{1}(u, S v),
$$

which is a contradiction. Therefore we get $u \in S v$. If $v \notin T u$, then similar contradiction can be obtained and we get $v \in T u$.

Hence, we can write $u \in S v \subseteq S T u$ and $v \in T u \subseteq T S v$, so $u$ and $v$ are fixed points of $S T$ and $T S$ respectively.

Now we introduce the concept of multivalued related F-contractions on two metric spaces, then we provide some results for such mappings.

Definition 3. Let $(X, d)$ and $(Y, \rho)$ be two metric spaces, $T: X \rightarrow C B(Y)$ and $S: Y \rightarrow C B(X)$ be two mappings. We say that $T$ and $S$ are multivalued related $F$-contractions if there exist $F \in \digamma$ and $\tau>0$ such that

$$
\begin{aligned}
H_{1}(S y, S z) & >0 \Longrightarrow \tau+F\left(H_{1}(S y, S z)\right) \leq F\left(M_{1}(x, y)\right), \\
H_{2}(T x, T w) & >0 \Longrightarrow \tau+F\left(H_{2}(T x, T w)\right) \leq F\left(M_{2}(x, y)\right)
\end{aligned}
$$

for all $x \in X$ and $y \in Y, z \in T x$ and $w \in S y$, where

$$
\begin{aligned}
& M_{1}(x, y)=\max \left\{D_{1}(x, S y), D_{1}(x, S z), \rho(y, z)\right\}, \\
& M_{2}(x, y)=\max \left\{D_{2}(y, T x), D_{2}(y, T w), d(x, w)\right\} .
\end{aligned}
$$


Before we give our main results, we recall the following. Let $X$ and $Y$ be two metric spaces. Then, a multivalued mapping $T: X \rightarrow P(Y)$ is said to be upper semicontinuous (lower semicontinuous) if the inverse image of closed sets (open sets) is closed (open). A multivalued mapping is continuous if it is upper as well as lower semicontinuous. If $T: X \rightarrow P(Y)$ is an upper semicontinuous and $\left\{x_{n}\right\},\left\{y_{n}\right\}$ be two sequences in $X$ and $Y$ respectively such that $x_{n} \rightarrow x, y_{n} \rightarrow y$ and $y_{n} \in T x_{n}$, then $y \in T x$.

New we can present the following assertion.

Theorem 6. Let $(X, d)$ and $(Y, \rho)$ be two complete metric spaces, $T: X \rightarrow K(Y)$ and $S: Y \rightarrow$ $K(X)$ be two multivalued related $F$-contractions. If $T$ and $S$ are upper semicontinuous or $F$ is continuous, then $S T$ has a fixed point $u \in X$ and TS has a fixed point $v \in Y$. Further, $v \in T u$ and $u \in S v$.

Proof. Let $x_{0}$ be an arbitrary point in $X$. As $S y$ and $T x$ are nonempty for all $x \in X$ and $y \in Y$, we can choose $y_{1} \in T x_{0}$ and $x_{1} \in S y_{1}$. Since $T x_{1}$ is compact then there exists $y_{2} \in T x_{1}$ such that

$$
\rho\left(y_{1}, y_{2}\right)=D_{2}\left(y_{1}, T x_{1}\right) .
$$

If $D_{2}\left(y_{1}, T x_{1}\right)=0$, then $y_{1} \in T x_{1} \subset T S y_{1}$ and $x_{1} \in S y_{1} \subset S T x_{1}$ and thus the proof is complete. Now suppose that $D_{2}\left(y_{1}, T x_{1}\right)>0$. From (F1) and (7), there exists $\tau>0$ such that

$$
F\left(D_{2}\left(y_{1}, T x_{1}\right)\right) \leq F\left(H_{2}\left(T x_{0}, T x_{1}\right)\right) \leq F\left(M_{2}\left(x_{0}, y_{1}\right)\right)-\tau \leq F\left(d\left(x_{0}, x_{1}\right)\right)-\tau .
$$

Therefore we obtain

$$
F\left(\rho\left(y_{1}, y_{2}\right)\right) \leq F\left(H_{2}\left(T x_{0}, T x_{1}\right)\right)<F\left(d\left(x_{0}, x_{1}\right)\right)-\tau \text {. }
$$

In a similar way, since $S y_{2}$ is compact then there exists $x_{2} \in S y_{2}$ such that

$$
d\left(x_{1}, x_{2}\right)=D_{1}\left(x_{1}, S y_{2}\right)
$$

If $D_{1}\left(x_{1}, S y_{2}\right)=0$, then $x_{1} \in S y_{2} \subset S T x_{1}$ and $y_{2} \in T x_{1} \subset T S y_{2}$ thus the proof is complete. Now suppose that $D_{1}\left(x_{1}, S y_{2}\right)>0$. From (F1) and (6), there exists $\tau>0$ such that

$$
F\left(D_{1}\left(x_{1}, S y_{2}\right)\right) \leq F\left(H_{1}\left(S y_{1}, S y_{2}\right)\right) \leq F\left(M_{1}\left(x_{1}, y_{1}\right)\right)-\tau \leq F\left(\rho\left(y_{1}, y_{2}\right)\right)-\tau .
$$

Therefore we obtain

$$
F\left(d\left(x_{1}, x_{2}\right)\right) \leq F\left(H_{1}\left(S y_{1}, S y_{2}\right)\right) \leq F\left(\rho\left(y_{1}, y_{2}\right)\right)-\tau
$$

By applying inequalities (8) and (9), we can construct two sequences $\left\{x_{n}\right\}$ and $\left\{y_{n}\right\}$ such that $x_{n} \in S y_{n}$ and $y_{n+1} \in T x_{n}$ for all $n \in \mathbb{N}$ satisfying

$$
\begin{aligned}
F\left(d\left(x_{n}, x_{n+1}\right)\right) & \leq F\left(\rho\left(y_{n}, y_{n+1}\right)\right)-\tau \leq F\left(d\left(x_{n-1}, x_{n}\right)-2 \tau\right. \\
& \vdots \\
& \leq F\left(\rho\left(y_{1}, y_{2}\right)\right)-(2 n-1) \tau \leq F\left(d\left(x_{0}, x_{1}\right)\right)-2 n \tau .
\end{aligned}
$$

Letting $n \rightarrow \infty$ and using (F2), we get

$$
\lim _{n \rightarrow \infty} d\left(x_{n}, x_{n+1}\right)=0 \quad \text { and } \quad \lim _{n \rightarrow \infty} \rho\left(y_{n}, y_{n+1}\right)=0 .
$$


Now denote $\alpha_{n}=d\left(x_{n}, x_{n+1}\right)$ for $n=0,1,2, \cdots$. From (F3) there exists $k \in(0,1)$ such that

$$
\lim _{n \rightarrow \infty} \alpha_{n}^{k} F\left(\alpha_{n}\right)=0
$$

By (10), the following holds for all $n \in \mathbb{N}$

$$
\alpha_{n}^{k} F\left(\alpha_{n}\right)-\alpha_{n}^{k} F\left(\alpha_{0}\right) \leq-2 \alpha_{n}^{k} n \tau \leq 0
$$

Letting $n \rightarrow \infty$ in (11), we get

$$
\lim _{n \rightarrow \infty} n \alpha_{n}^{k}=0
$$

From (12) there exists $n_{1} \in \mathbb{N}$ such that $n \alpha_{n}^{k} \leq 1$ for all $n>n_{1}$. So we have

$$
\alpha_{n} \leq \frac{1}{n^{\frac{1}{k}}}
$$

for all $n>n_{1}$. In order to show that $\left\{x_{n}\right\}$ is Cauchy sequence consider $m, n \in \mathbb{N}$ such that $m>n$. From (13) and triangular inequality we can write

$$
d\left(x_{n}, x_{m}\right) \leq \sum_{i=n}^{m-1} d\left(x_{i}, x_{i+1}\right)=\sum_{i=n}^{m-1} \alpha_{i} \leq \sum_{i=n}^{m-1} \frac{1}{i \frac{1}{k}} .
$$

By the convergence of the series $\sum_{i=1}^{\infty} \frac{1}{i \frac{1}{k}}$ we have that $\left\{x_{n}\right\}$ is Cauchy sequence in $(X, d)$. Similarly we can see that $\left\{y_{n}\right\}$ is Cauchy sequence in $(Y, \rho)$. Since $(X, d)$ and $(Y, \rho)$ are complete metric spaces, the sequences $\left\{x_{n}\right\}$ and $\left\{y_{n}\right\}$ converge to some point $u \in X$ and $v \in Y$ respectively.

Now suppose $T$ and $S$ are upper semicontinuous. Since $x_{n} \in S y_{n}, y_{n+1} \in T x_{n}, x_{n} \rightarrow u$ and $y_{n} \rightarrow v$, we have $u \in S v$ and $v \in T u$. Therefore $u$ and $v$ are fixed points of ST and TS, respectively.

Now suppose $F$ is continuous and $u \notin S v$ or $v \notin T u$. If $u \notin S v$, then there exists $n_{0} \in \mathbb{N}$ such that $D_{1}\left(S v, x_{n+1}\right)>0$ for $n>n_{0}$. Therefore, applying inequality (6) and (F1), we have

$$
\begin{aligned}
F\left(D_{1}\left(S v, x_{n+1}\right)\right) & \leq F\left(H_{1}\left(S v, S y_{n+1}\right)\right) \leq F\left(M_{1}\left(x_{n}, v\right)\right)-\tau \\
& \leq F\left(\max \left\{D_{1}\left(x_{n}, S v\right), D_{1}\left(x_{n}, S y_{n+1}\right), \rho\left(v, y_{n+1}\right)\right\}\right)-\tau \\
& \leq F\left(\max \left\{D_{1}\left(x_{n}, S v\right), d\left(x_{n}, x_{n+1}\right), \rho\left(v, y_{n+1}\right)\right\}\right)-\tau .
\end{aligned}
$$

Letting $n \rightarrow \infty$ and using the continuity of $F$, we get

$$
F\left(D_{1}(S v, u)\right) \leq F\left(D_{1}(u, S v)\right)-\tau
$$

which is a contradiction. Therefore we get $u \in S v$. If $v \notin T u$, then similar contradiction can be obtained and we get $v \in T u$. Hence, we can write $u \in S v \subseteq S T u$ and $v \in T u \subseteq T S v$, so $u$ and $v$ are fixed points of $S T$ and $T S$ respectively. 
The following example shows that the compactness of $T x$ and $S y$ can not be relaxed in Theorem 6.

Example 1. Let $(X, d)$ and $(Y, \rho)$ be two metric spaces such that $X=[0,1], Y=[-1,0]$ and $d=\rho$ with

$$
d(x, y)=\left\{\begin{array}{cc}
0, & x=y \\
1+|x-y|, & x \neq y
\end{array}\right.
$$

Define two mappings $T: X \rightarrow P(Y)$ and $S: Y \rightarrow P(X)$ by

$$
T x=\left\{\begin{array}{c}
Q_{Y}, \quad x \in I_{X}, \\
I_{Y}, \quad x \in Q_{X},
\end{array} \quad \text { and } \quad S y=\left\{\begin{array}{cc}
I_{X}, & y \in I_{Y}, \\
Q_{X}, & y \in Q_{Y},
\end{array}\right.\right.
$$

where $Q_{A}$ and $I_{A}$ are rational and irrational numbers in $A$, respectively. Note that $(X, d)$ and $(Y, \rho)$ are complete metric spaces. Moreover, every subsets of $X$ as well as $Y$ are closed but noncompact because of $\tau_{d}$ and $\tau_{\rho}$ are discrete topologies. This also shows that $T$ and $S$ are upper semicontinuous. Furthermore, the spaces $X$ and $Y$ are bounded and so TX and Sy are closed and bounded. Now define $F:(0, \infty) \rightarrow \mathbb{R}$ by

$$
F(\alpha)=\left\{\begin{array}{cc}
\ln \alpha, & \alpha \leq 1 \\
\alpha, & \alpha>1
\end{array}\right.
$$

then it is clear that $F \in \digamma \backslash \digamma_{*}$. Now we show that the inequalities (6) and (7) are satisfied with $\tau=1$. First note that, if $x \in X, y \in Y$ and $z \in T x$ with $H_{1}(S y, S z)>0$, then $x \in I_{X}$ and $y \in I_{Y}$ or $x \in Q_{X}$ and $y \in Q_{Y}$. Hence, we have to consider the following two cases.

Case 1. Let $x \in I_{X}$ and $y \in I_{Y}$. Then for all $z \in T x=Q_{Y}$, we have $H_{1}(S y, S z)=1>0$ and

$$
\tau+F\left(H_{1}(S y, S z)\right)=1+F(1)=1<1+|y-z|=\rho(y, z)=F(\rho(y, z)) \leq F\left(M_{1}(x, y)\right) .
$$

Case 2. Let $x \in Q_{X}$ and $y \in Q_{Y}$. Then for all $z \in T x=I_{Y}$, we have $H_{1}(S y, S z)=1>0$ and

$$
\tau+F\left(H_{1}(S y, S z)\right)=1+F(1)=1<1+|y-z|=\rho(y, z)=F(\rho(y, z)) \leq F\left(M_{1}(x, y)\right) .
$$

Therefore (6) holds. Similarly, we can see that (7) holds. As a consequence, all conditions of Theorem 6 except of the compactness of Tx and Sy are satisfied, but TS and ST do not have fixed points.

Remark 2. Considering the family $\digamma_{*}$ in Theorem 6, we can relaxed the compactness condition on Tx and Sy as closed and boundedness. Therefore, it gives us the following theorem.

Theorem 7. Let $(X, d)$ and $(Y, \rho)$ be two complete metric spaces, $T: X \rightarrow C B(Y)$ and $S$ : $Y \rightarrow C B(X)$ be two multivalued related $F$-contractions with $F \in \digamma_{*}$. If $T$ and $S$ are upper semicontinuous or $F$ is continuous, then ST has a fixed point $u \in X$ and TS has a fixed point $v \in Y$. Further, $v \in T u$ and $u \in S v$.

Proof. Let $x_{0} \in X$. As $S y$ and $T x$ are nonempty for all $x \in X$ and $y \in Y$, we can choose $y_{1} \in T x_{0}$ and $x_{1} \in S y_{1}$. If $D_{2}\left(y_{1}, T x_{1}\right)=0$ then $y_{1} \in T x_{1}$. So we obtain $y_{1} \in T x_{1} \subset T S y_{1}$ and $x_{1} \in S y_{1} \subset S T x_{1}$ mean that $x_{1}$ and $y_{1}$ are the fixed points of ST and TS respectively. Now let $D_{2}\left(y_{1}, T x_{1}\right)>0$. Since $D_{2}\left(y_{1}, T x_{1}\right) \leq H_{2}\left(T x_{0}, T x_{1}\right)$, we have

$$
F\left(D_{2}\left(y_{1}, T x_{1}\right)\right) \leq F\left(H_{2}\left(T x_{0}, T x_{1}\right)\right) \leq F\left(M_{2}\left(x_{0}, y_{1}\right)\right)-\tau \leq F\left(d\left(x_{0}, x_{1}\right)\right)-\tau .
$$


From (F4) we write

$$
F\left(D_{2}\left(y_{1}, T x_{1}\right)\right)=\inf _{y \in T x_{1}} F\left(\rho\left(y_{1}, y\right)\right) \leq F\left(d\left(x_{0}, x_{1}\right)\right)-\tau .
$$

From (14) there exists $y_{2} \in T x_{1}$ such that

$$
F\left(\rho\left(y_{1}, y_{2}\right)\right) \leq F\left(d\left(x_{0}, x_{1}\right)\right)-\tau .
$$

In the similar way, if $D_{1}\left(x_{1}, S y_{2}\right)=0$, then $x_{1} \in S y_{2}$. So we get $x_{1} \in S y_{2} \subset S T x_{1}$ and $y_{2} \in$ $T x_{1} \subset T S y_{1}$ mean that $x_{1}$ and $y_{1}$ are the fixed points of $S T$ and TS respectively. Otherwise, since $D_{1}\left(x_{1}, S y_{2}\right) \leq H_{1}\left(S y_{1}, S y_{2}\right)$, we have

$$
F\left(D_{1}\left(x_{1}, S y_{2}\right)\right) \leq F\left(H_{1}\left(S y_{1}, S y_{2}\right)\right) \leq F\left(M\left(x_{1}, y_{1}\right)\right)-\tau \leq F\left(\rho\left(y_{1}, y_{2}\right)\right)-\tau .
$$

Hence, from (F4) we obtain

$$
F\left(D_{1}\left(x_{1}, S y_{2}\right)\right)=\inf _{x \in S y_{2}} F\left(d\left(x_{1}, x\right)\right) \leq F\left(\rho\left(y_{1}, y_{2}\right)\right)-\tau .
$$

Therefore, from (15) there exists $x_{2} \in S y_{2}$ such that

$$
F\left(d\left(x_{1}, x_{2}\right) \leq F\left(\rho\left(y_{1}, y_{2}\right)\right)-\tau .\right.
$$

The rest of the proof can be completed as in the proof of Theorem 6 .

If we choose $X=Y, S=T$ and $d=\rho$ in the above theorems we obtain the following fixed point results.

Corollary 1. Let $(X, d)$ be a complete metric space, $T: X \rightarrow K(X)$ be a mapping such that for all $x, y \in X$ and $z \in T x$

$$
H(T y, T z)>0 \Longrightarrow \tau+F(H(T y, T z)) \leq F(M(x, y))
$$

holds, where $F \in \digamma, \tau>0$ and

$$
M(x, y)=\max \{D(x, T y), D(x, T z), d(y, z)\} .
$$

If $T$ is upper semicontinuous or $F$ is continuous, then $T^{2}$ has a fixed point in $X$.

Corollary 2. Let $(X, d)$ be a complete metric space, $T: X \rightarrow C B(X)$ be a mapping such that for all $x, y \in X$ and $z \in T x$

$$
H(T y, T z)>0 \Longrightarrow \tau+F(H(T y, T z)) \leq F(M(x, y))
$$

holds, where $F \in \digamma_{*}, \tau>0$ and

$$
M(x, y)=\max \{D(x, T y), D(x, T z), d(y, z)\} .
$$

If $T$ is upper semicontinuous or $F$ is continuous, then $T^{2}$ has a fixed point in $X$.

\section{ACKNOWLEDGEMENT}

The authors are thankful to the referee for making valuable suggestions leading to the better presentations of the paper. 


\section{REFERENCES}

[1] Agarwal R.P., O'Regan D., Sahu D.R. Fixed point theory for Lipschitzian-type mappings with applications. Springer, New York, 2009.

[2] Altun I., Durmaz G., Minak G., Romaguera S. Multivalued almost F-contractions on complete metric spaces. Filomat 2016, 30 (2), 441-448.

[3] Altun I., Minak G., Dag H. Multivalued F-contractions on complete metric space. J. Nonlinear Convex Anal. 2015, $16(4), 659-666$.

[4] Fisher B. Fixed points on two metric spaces. Glas. Mat. Ser. III 1981, 16 (36), 333-337.

[5] Fisher B. Related fixed points on two metric spaces. Math. Sem. Notes Kobe Univ. 1982, 10, 17-26.

[6] Fisher B., Jain R.K., Sahu H.K. Related fixed point theorems for three metric spaces. Novi Sad J. Math. 1996, 26 (1), 11-17.

[7] Fisher B., Namdeo R.K., Gupta D. A related fixed point theorem on two metric spaces. Punjab Univ. J. Math. 1994, 27, 109-112.

[8] Wardowski D. Fixed points of a new type of contractive mappings in complete metric spaces. Fixed Point Theory Appl. 2012, 2012, article number 94. doi:10.1186/1687-1812-2012-94

[9] Nadler S.B. Multi-valued contraction mappings. Pacific J. Math. 1969, 30, 475-488.

Received 04.11.2019

Revised 01.05.2020

Бічер О., Олгун М., Алілдіз Т., Алтун I. Аеякі пов'язані теореми про нерухому точку для багатозначних відображень на двох метричних просторах // Карпатські матем. публ. - 2020. — Т.12, №2. - С. 392-400.

Означення пов'язаних відображень було введено Фішером у 1981 р. Він довів деякі теореми про існування нерухомих точок однозначних відображень, визначених на двох повних метричних просторах, і відношення між цими відображеннями. У цій роботі ми подаємо деякі результати про пов' язану нерухому точку для багатозначних відображень на двох повних метричних просторах. Спочатку ми даємо класичний результат, який $є$ продовженням основного результату Фішера до багатозначного випадку. Потім, розглядаючи нову техніку Вардовського, за допомогою умов типу Ғ-стиску ми пропонуємо два результати про пов' язану нерухому точку як для компактозначних відображень, так і для відображень, значеннями яких $є$ замкнені обмежені множини.

Ключові слова і фрази: нерухома точка, повний метричний простір, F-стиск. 